
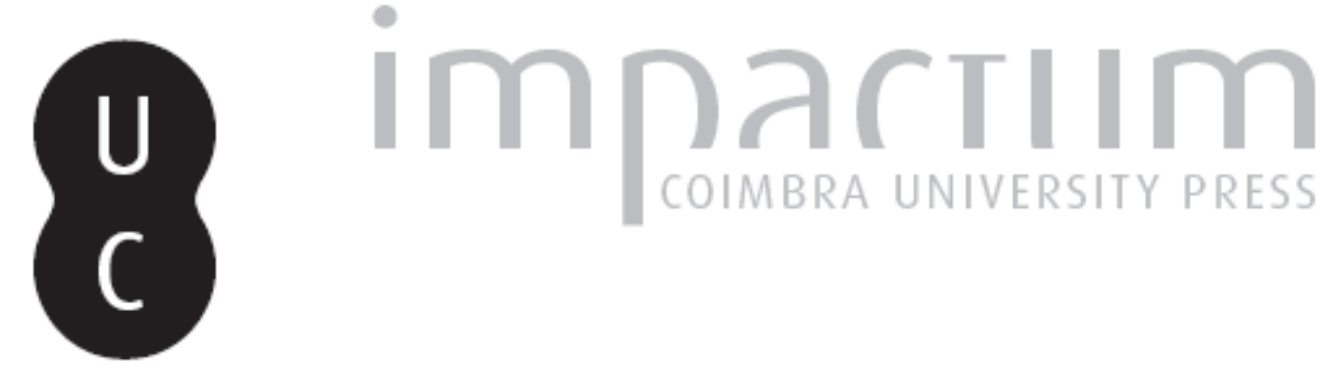

\title{
O Santo Ofício no tempo dos Filipes: transformações institucionais e relações de poder
}

Autor(es): López-Salazar Codes, Ana Isabel

Publicado por: Centro de História da Sociedade e da Cultura

URL persistente:

URI:http://hdl.handle.net/10316.2/39580

DOI:

DOI:http://dx.doi.org/10.14195/1645-2259_9_5

Accessed : $\quad$ 26-Apr-2023 15:48:24

A navegação consulta e descarregamento dos títulos inseridos nas Bibliotecas Digitais UC Digitalis, UC Pombalina e UC Impactum, pressupõem a aceitação plena e sem reservas dos Termos e Condições de Uso destas Bibliotecas Digitais, disponíveis em https://digitalis.uc.pt/pt-pt/termos.

Conforme exposto nos referidos Termos e Condições de Uso, o descarregamento de títulos de acesso restrito requer uma licença válida de autorização devendo o utilizador aceder ao(s) documento(s) a partir de um endereço de IP da instituição detentora da supramencionada licença.

Ao utilizador é apenas permitido o descarregamento para uso pessoal, pelo que o emprego do(s) título(s) descarregado(s) para outro fim, designadamente comercial, carece de autorização do respetivo autor ou editor da obra.

Na medida em que todas as obras da UC Digitalis se encontram protegidas pelo Código do Direito de Autor e Direitos Conexos e demais legislação aplicável, toda a cópia, parcial ou total, deste documento, nos casos em que é legalmente admitida, deverá conter ou fazer-se acompanhar por este aviso.

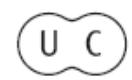



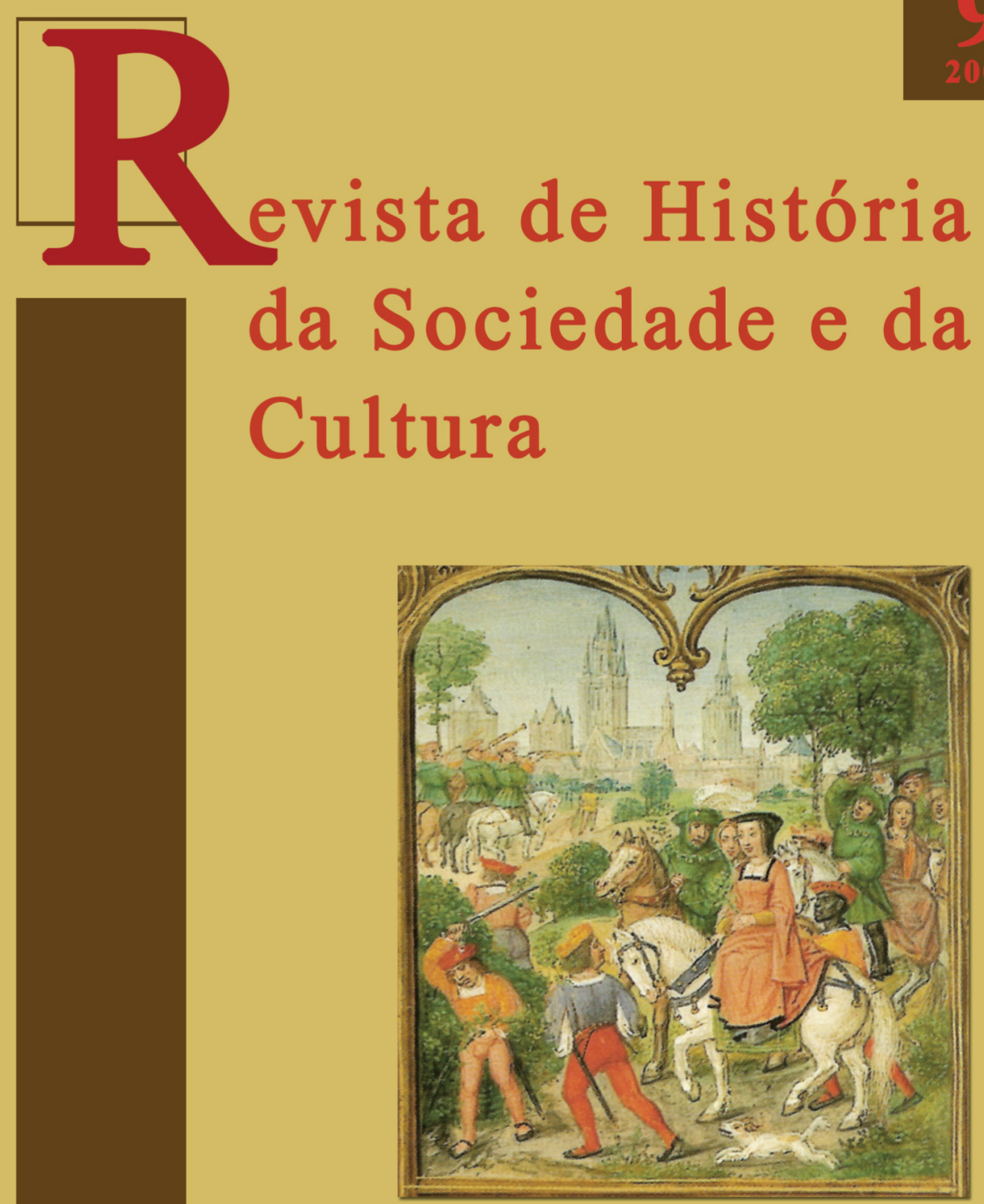

Centro de História da Sociedade e da Cultura Universidade de Coimbra

Coimbra 


\title{
O Santo Ofício no tempo dos Filipes: transformações institucionais e relações de poder*
}

\author{
Ana Isabel López-Salazar Codes \\ Universidad de Castilla-La Mancha. Facultad de Letras. \\ CIDEHUS-Universidade de Évora \\ ailopezsalazar@hotmail.com
}

Texto entregue em/Text submited on: 04/04/2009

\section{Resumo/Abstract:}

Durante o período filipino, o Santo Ofício sofreu diversas transformações institucionais e sociológicas que sobreviveram à ruptura de Dezembro de 1640. Neste artigo estudaremos a evolução do cargo de inquisidor-mor e do Conselho Geral, assim como os mecanismos de comunicação estabelecidos entre estes organismos centrais do governo do Santo Ofício, os quais permaneceram em Lisboa, e a Coroa, naquela altura quase sempre sediada em Madrid. Do mesmo modo, analisaremos os traços gerais das relações de poder entre o Santo Ofício e as restantes instituições eclesiásticas (bispos, cabidos e colector) e seculares (tribunais superiores e conselhos) do Portugal filipino. Por último, centrar-nos-emos na actuação política dos ministros do Tribunal da Fé durante as crises de 1580 e de 1640.

During the Philippine epoch the Holy Office underwent several institutional and sociological changes that survived the plot of December 1640. This paper will focus on the development of the office of the Grand Inquisitor and the General Council, as well as the communication mechanisms established between the governing bodies of the Holy Office (which remained in Lisbon) and the Crown, at the time mostly based in Madrid. In parallel, it analyses the general features of the power relationships between the Holy Office and the other ecclesiastical (bishops, chapter and collector) and secular institutions (high courts and councils). Finally, it describes the political actions of the ministers of the Inquisition during the crises of 1580 and 1640.

Palavras chave/Key words:

Governo filipino; Sistema polissinodal; Inquisição; Conselho Geral do Santo Ofício; Inquisidor-geral.

Philippine age; Multi-synodal system; Inquisition; General Council of the Holy Office; Grand inquisitor.

* Este trabalho integra-se no projecto de investigação Inquirir da honra. Os comissários do Santo Ofício e das Ordens Militares em Portugal (1570-1773), financiado pela Fundação para a Ciência e a Tecnologia (PTDC/HAH/64160/2006). Agradecemos a Susana Mateus o auxílio na revisão da forma portuguesa do texto. 


\section{Introdução}

Em 1987, no artigo intitulado "Em busca dos tempos da Inquisição", Joaquim Romero Magalhães expôs duas ideias fundamentais que, em seu entender, deviam guiar as investigações sobre o Santo Ofício português ${ }^{1}$. Assim, considerava imprescindível devolver o protagonismo à instituição inquisitorial, como forma de compreender a sua evolução ao longo dos quase três séculos de existência, e estudar as relações entre este Tribunal e os restantes poderes do Reino. No tocante ao devir político e institucional do Santo Ofício, a historiografia tem-lhe conferido ainda pouca atenção, devido, em parte, ao seu maior interesse por estudar a repressão às heresias, especialmente a judaizante. No entanto, dispomos do notável trabalho de Francisco Bethencourt sobre as Inquisições da Época Moderna, que também se debruça sobre alguns aspectos institucionais e sociológicos do Tribunal português ${ }^{2}$. Por seu turno, as relações entre o Santo Ofício e outras instituições eclesiásticas, nomeadamente os bispos e as ordens religiosas (dominicanos e jesuítas), têm sido objecto de diversos estudos por parte de José Pedro Paiva e de Giuseppe Marcocci³.

A maior parte dos trabalhos sobre a Inquisição portuguesa têm privilegiado, devido ao seu inquestionável interesse, o tempo do estabelecimento do Tribunal e do seu governo pelo cardeal infante D. Henrique. Pelo contrário, apesar de no último quarto de século ter ocorrido um aumento das investigações sobre o Portugal dos Filipes, motivado, entre outras razões, pelo ressur-

1 MAGALHÃES, Joaquim Romero - Em busca dos "tempos" da Inquisição (1573-1615). Revista de História das Ideias. 9 (1987) 191-192.

2 BETHENCOURT, Francisco - História das Inquisições. Portugal, Espanha e Itália. Lisboa: Círculo de Leitores, 1994.

3 PAIVA, José Pedro - Inquisição e visitas pastorais. Dois mecanismos complementares de controle social?. Revista de História das Ideias. 11 (1989) 85-102. PAIVA, José Pedro Os bispos e a Inquisição portuguesa (1536-1613). Lusitania sacra. 2a série, XV (2003) 43-76. PAIVA, José Pedro - Os dominicanos e a Inquisição em Portugal (1536-1614). NW noroeste, revista de história. 1 (2005) 167-229. MARCOCCI, Giuseppe - I custodi dell'ortodossia. Inquisizione e Chiesa nel Portogallo del Cinquecento. Roma: Edizione di Storia e Letteratura, 2004. MARCOCCI, Giuseppe - «Catequização pelo medo»? Inquisitori, vescovi e confessori di fronte ai «nuovi cristiani» nel Portogallo del Cinquecento in Le Inquisizioni cristiane e gli ebrei. Roma: Accademia Nazionale dei Lincei, 2003, p. 123-193. MARCOCCI, Giuseppe - Inquisição, jesuítas e cristãos-novos em Portugal no século XVI. Revista de História das Ideias. 25 (2004) 247-326. 
gimento e renovação da história político-institucional, temos ainda poucos estudos sobre o Tribunal durante a União Ibérica. No entanto, não podemos esquecer os recentes trabalhos de Ignacio Pulido Serrano sobre as relações entre a Monarquia Hispânica, os cristãos-novos e as Inquisições de Espanha e Portugal ${ }^{4}$.

De acordo com os pressupostos traçados por Romero Magalhães, e a fim de contribuir para o melhor conhecimento da Inquisição portuguesa no tempo dos Filipes, no presente artigo analisaremos, embora de forma muito sucinta, a evolução e as transformações político-institucionais, governativas e sociológicas que o Tribunal sofreu durante a União Ibérica, assim como a sua relação com as restantes instituições e poderes eclesiásticos e seculares do Reino 5 .

\section{O inquisidor mor}

Durante o tempo da União Ibérica, a transformação mais importante relativa ao cargo de inquisidor mor ou inquisidor geral foi o estabelecimento da obrigação de o eleito resignar ao bispado de que era titular para poder desempenhar o cargo no Tribunal da Fé. Até ao reinado de D. Filipe III, na realidade até 1599 , o inquisidor geral era um prelado que, em simultâneo, mantinha e conservava o governo da sua diocese. O caso do cardeal D. Henrique é paradigmático, pois acumulou a chefia da Inquisição com a sua condição de arcebispo de Évora, primeiro, e de arcebispo de Lisboa, depois. Contudo, depois dele, também D. Jorge de Almeida e o cardeal arquiduque Alberto foram inquisidores gerais e arcebispos, respectivamente, de Lisboa e eleito - embora não consagrado - de Toledo. Finalmente,

4 PULIDO SERRANO, Juan Ignacio - Injurias a Cristo. Religión, política y antijudaísmo en el siglo XVII. Madrid: Instituto Internacional de Estudios Sefardíes y Andalusíes Universidad de Alcalá, 2002. PULIDO SERRANO, Juan Ignacio - Os Judeus e a Inquisição no Tempo dos Filipes. Lisboa: Campo da Comunicação, 2007.

5 Este artigo retoma, sucintamente, as principais conclusões da nossa tese de doutoramento Poder y ortodoxia. El gobierno del Santo Oficio en el Portugal de los Austrias (1578-1653), defendida na Facultad de Letras de Ciudad Real (Universidad de Castilla - La Mancha), em Maio de 2008. Para evitar erros e confusões, optámos por manter a designação castelhana dos reis da casa de Áustria e não a portuguesa. 
D. António Matos de Noronha desempenhou o cargo ao mesmo tempo que era bispo de Elvas.

Em 1599, o papa Clemente VIII, a pedido de D. Filipe III, revogou todas as licenças concedidas aos bispos para poderem residir fora das suas dioceses $^{6}$. Como consequência, D. António Matos de Noronha, inquisidor geral, e D. Pedro de Castilho, presidente do Desembargo do Paço, tiveram de renunciar aos seus cargos para conservarem os seus bispados, respectivamente de Elvas e de Leiria ${ }^{7}$. As razões destas mudanças foram tanto políticas como religiosas. Relacionavam-se com as transformações motivadas pelo início da privança do duque de Lerma e da sua política de feituras e com o contexto político português, isto é, com as pressões dos cristãos-novos para conseguirem um perdão geral das culpas de judaísmo. Mas, em nosso entender, o motivo principal e primeiro era de cariz religioso. D. Filipe III, como o resto dos monarcas da casa de Áustria, considerava que os prelados deviam residir nas suas igrejas ${ }^{8}$. Nesse momento, abriu-se um período de crise no cargo de inquisidor geral que não se resolveu até à chegada a Lisboa de D. Pedro de Castilho, em finais de 1604.

A partir de D. Pedro de Castilho, todos os inquisidores gerais tiveram que renunciar aos seus bispados para poderem exercer o cargo no Tribunal da Fé. Isso teve duas consequências. Por um lado, a Coroa deveria fornecer as bases económicas para a manutenção do inquisidor geral, mediante a atribuição de um ordenado fixo9. Além disso, todos os inquisidores gerais seguintes tiveram pensões impostas em diferentes bispados e nas rendas do fisco da Inquisição. Mas, por outro lado, a obrigação de deixarem o governo

${ }^{6}$ Bullarium Romamnum, Roma, Typ. Mainardi, 1735, tomo X, p. 478-481.

7 No dia 12 de Fevereiro de 1600, Clemente VIII destituíu D. António Matos de Noronha do cargo de inquisidor geral. Poucos dias antes, tinha nomeado D. Jorge de Ataíde para o substituir. Archivio Segreto Vaticano (ASV) - Segreteria dei Brevi (SB), vol. 292, fl. 62r-65r: Breve Cum nos nuper (7-II-1600). ASV - SB, vol. 359, fl. 98r-98v: Breve Ecclesiarum praesulatus (12-II-1600).

8 Cf. PAIVA, José Pedro - Os Bispos de Portugal e do Império. 1495-1777. Coimbra: Imprensa da Universidade de Coimbra, 2006, p. 390-391.

9 D. Pedro de Castilho foi o primeiro inquisidor geral português que teve um ordenado relativo ao exercício do cargo. A sua verba foi estabelecida em 2.500 cruzados durante toda a União Dinástica. Arquivo Nacional da Torre do Tombo (ANTT) - Conselho Geral do Santo Ofício (CGSO), liv. 88, Portarias, fl. 7, Carta de D. Filipe III ao Conselho Geral (8-VI-1604). 
episcopal explica, entre outras razões, por que é que não houve nenhum arcebispo a desempenhar o lugar de inquisidor geral durante o tempo dos Áustrias ${ }^{10}$. O governo do Tribunal da Fé era, sem dúvida, prestigiante, mas não podia comparar-se à primazia do arcebispado de Braga, à riqueza do de Évora ou à relevância política do de Lisboa.

Durante a União Ibérica, os reis escolheram sempre para ocuparem os mais altos cargos da hierarquia da Igreja pessoas que deviam a sua carreira política e eclesiástica à fidelidade à Coroa. Para além do cardeal arquiduque Alberto e de D. Alexandre de Bragança, filho dos duques D. João e D. Catarina de Bragança, os três primeiros inquisidores gerais nomeados pelos Filipes tinham estabelecido os seus vínculos com a casa de Áustria durante o tempo da crise dinástica. D. António Matos de Noronha, D. Jorge de Ataíde e D. Pedro de Castilho tinham apoiado, sem hesitação, D. Filipe II durante o reinado do cardeal D. Henrique ${ }^{11}$. E, embora D. Fernão Martins Mascarenhas fosse ainda relativamente novo nessa altura, a sua família tinha-se vinculado à causa filipina. O seu irmão D. João de Mascarenhas, mordomo-mor do cardeal-rei D. Henrique, colaborou com D. Cristóvão de Moura, a quem revelava o teor dos assuntos tratados no Conselho de Estado português. E, em 1593, D. Filipe II escolheu o seu tio D. Francisco Mascarenhas como um dos governadores do Reino. Só D. Francisco de Castro, um menino de seis anos quando teve lugar a União Ibérica, cujos pai e irmãos mais velhos tinham morrido em Alcácer-Quibir, desenvolveu toda a sua carreira político-eclesiástica já durante o governo filipino. Mas, se não tinha participado na crise de 1580, teve um papel fundamental na de 1640, como se verá adiante.

${ }^{10}$ Em 1601, D. Cristóvão de Moura, vice-rei de Portugal, propôs D. Miguel de Castro, arcebispo de Lisboa, para o cargo de inquisidor geral, mas D. Filipe III rejeitou a proposta porque, embora o prelado continuasse a residir em Lisboa, não poderia cumprir com a obrigação da visita pastoral pelo distrito. Archivo Histórico Nacional (AHN) - Estado, lib. 81, fl. 86, Carta de D. Filipe III a D. Cristóvão de Moura (26-II-1602).

${ }^{11}$ Sobre a actividade de D. António Matos de Noronha para conseguir adeptos à causa filipina durante o reinado de D. Henrique remetemos para a nossa tese de doutoramento Poder y ortodoxia ..., cit., p. 62-69. Sobre D. Jorge de Ataíde ver PAIVA, José Pedro - Os Bispos de Portugal..., cit., p. 176 e 373. Para o caso de D. Pedro de Castilho ver VEIGA, Carlos Margaça - D. Pedro de Castilho: esboço de uma carreira no Governo Espanhol de Portugal in Primeiras Jornadas de História Moderna. Lisboa: Centro de História da Universidade de Lisboa, 1989, p. 355-370. 


\section{O Conselho Geral}

Embora existente quase desde o estabelecimento do Tribunal, o Conselho Geral do Santo Ofício foi instituído oficial e formalmente a 14 de Junho de 1569 pelo inquisidor mor D. Henrique. Segundo estabelecia o seu regimento, assinado pelo cardeal a 1 de Março de 1570, devia contar com três deputados, todos nomeados pelo inquisidor geral, e um secretário. Apesar do regimento ordenar apenas que esses deputados fossem eclesiásticos, rapidamente se impôs o costume de promover para o Conselho inquisidores e deputados dos tribunais de distrito ${ }^{12}$. O motivo maior que justificava esta opção era evidente: tratava-se de pessoas com experiência nas questões inquisitoriais. Além disso, reforçava-se, deste modo, o poder do inquisidor geral, visto que este controlava toda a promoção na carreira inquisitorial, para além do facto de o Conselho ser uma excelente porta de acesso aos bispados do Reino.

Durante o tempo dos Filipes, o Conselho conheceu profundas e duradouras transformações tanto institucionais como sociológicas, algumas das quais causadas pela intervenção da Coroa e, num ou noutro caso, pela influência do Santo Ofício espanhol. Do ponto de vista institucional, a actuação da Coroa sobre o Conselho manifestou-se em três questões. Em primeiro lugar, durante o reinado de D. Filipe III o número de deputados foi aumentado de três para seis. Nas duas juntas para a reforma do Santo Ofício que se reuniram em Valhadolid, em 1603 e 1604, acordou-se que o Conselho fosse constituído por cinco membros ${ }^{13}$. Mas, embora Felipe III tivesse ordenado o cumprimento dos capítulos destas juntas, a nomeação dos novos deputados

${ }^{12}$ Entre 1569 e 1642, dos trinta e nove deputados do Conselho, só oito procediam de fora do Tribunal da Fé. Destes, quatro foram nomeados antes da União Ibérica, três ocuparam o lugar reservado a partir de 1614 à ordem de São Domingos e um, D. António Matos de Noronha, bispo de Elvas e antigo conselheiro da Suprema em Espanha, foi escolhido pelo cardeal arquiduque Alberto para o cargo de presidente.

${ }^{13}$ Biblioteca Nacional de Lisboa (BNL) - Fundo Geral (FG), cód. 1537, fl. 106r-115v, Juntas que se fiserão por mandado de elrey Felippe $2^{\circ}$ para reformar o Regimento do Santo Officio, capítulo 8. Os capítulos da primeira junta foram ajustados em 21 de Setembro de 1603 e os da segunda em 20 de Setembro de 1604. Sobre as juntas de Valhadolid e o contexto das relações entre o Santo Ofício e a Monarquía Hispânica em que se reuniram ver LÓPEZ-SALAZAR CODES, Ana Isabel - Inquisição, cristãos novos e Monarquía Hispânica em tempos do perdão geral de 1605. Lisboa: Cátedra de Estudos Sefarditas "Alberto Benveniste", 2009 (no prelo). 
não aconteceu, até Janeiro de 1610, por iniciativa do inquisidor geral D. Pedro de Castilho ${ }^{14}$. E, em 1614, também D. Filipe III fez mercê à Ordem de São Domingos de um assento perpétuo no Conselho ${ }^{15}$.

Em segundo lugar, durante o tempo dos Áustrias, projectou-se a criação do cargo de presidente do Conselho Geral. Quando o cardeal arquiduque Alberto voltou para Castela, deixou como presidente do Conselho D. António Matos de Noronha, bispo de Elvas e antigo conselheiro da Suprema, em Espanha. Em Agosto de 1595, quando o arquiduque foi nomeado capitão-geral do exército da Flandres, concedeu a Matos de Noronha todos os poderes associados ao cargo de inquisidor gera ${ }^{16}$. A ideia de nomear um presidente reapareceu em 1628, depois da morte do inquisidor geral D. Fernão Martins Mascarenhas. Numa altura em que as relações entre a coroa e o Santo Ofício eram especialmente complicadas, devido à questão dos cristãos novos, D. Filipe IV pensou na nomeação de um presidente que regesse o Santo Ofício até à designação de um novo inquisidor geral. Mas, tanto os governadores de Portugal como o Conselho opuseram-se, porque temiam que o rei escolhesse uma pessoa sem as qualidades necessárias e, eventualmente, até um castelhano. Além disso, consideravam que esta escolha podia atrasar a provisão do novo inquisidor geral ${ }^{17}$.

Por último, os Filipes tentaram introduzir em Portugal o sistema espanhol de eleição de deputados. Em Espanha, o inquisidor geral devia propor ao monarca três pessoas para cada lugar de conselheiro da Suprema que estivesse vago. Em 1610 e 1611, D. Filipe III ordenou a D. Pedro de Castilho que nomeasse três eclesiásticos para cada um dos dois lugares do Conselho vacantes pela morte de Marcos Teixeira e de Manuel Álvares Tavares.

${ }^{14}$ Em Janeiro de 1610, o Conselho era constituído por Marcos Teixeira, Bartolomeu da Fonseca e Rui Pires da Veiga. Nessa altura, D. Pedro de Castilho informou D. Filipe III que, para aumentar o seu número para cinco, pensava promover Manuel Álvares Tavares e António Dias Cardoso. Biblioteca da Ajuda (BA) - Governo de Portugal (GP), cód. 51-VIII-17, fl. 130r, D. Pedro de Castilho a D. Filipe III (20-I-1610).

${ }^{15}$ Sobre as relações entre o Santo Ofício e os dominicanos desde o estabelecimento do Tribunal até ao momento em que D. Filipe III outorgou à Ordem esta mercê é fundamental o trabalho de PAIVA, José Pedro - Os dominicanos e a Inquisição..., cit.

${ }^{16}$ ANTT - CGSO, liv. 136, fl. 78r-78v e 79v-80r, Provisões do cardeal arquiduque Alberto (7-VIII-1593 e 5-VIII-1595).

${ }^{17}$ ASV - Segreteria di Stato (SS), Portogallo, no 17, fl. 359r-359v e 365r, cartas do colector Lorenzo Tramallo (2 e 16-IX-1628). 
Apesar de nesta altura o inquisidor geral ter obedecido ao monarca e embora duas juntas reunidas em Madrid, em 1623 e 1634, tivessem recomendado a imposição em Portugal da prática espanhola, D. Filipe IV decidiu respeitar o sistema tradicional português ${ }^{18}$.

Não foram menos relevantes as transformações sociológicas do Conselho Geral. Até ao reinado de D. Filipe IV, foi integrado por juristas procedentes de grandes famílias de letrados, como Rui Pires da Viega ou António e Sebastião de Matos de Noronha, ou da chamada gente nobre da governança da terra, como João Álvares Brandão ou Gaspar Pereira. Mas, desde o governo do inquisidor geral D. Fernão Martins Mascarenhas, isto é, a partir de 1617, para além de sujeitos com o perfil assinalado, começaram a ingressar no Conselho membros da fidalguia, como D. Francisco de Bragança, D. João da Silva, frei João de Portugal, D. Miguel de Castro ou D. Miguel de Portugal. Além disso, desde 1617 aumentou consideravelmente o número de deputados provenientes dos colégios maiores de São Pedro e São Paulo da Universidade de Coimbra. Não podemos esquecer que, tanto D. Fernão Martins Mascarenhas como D. Francisco de Castro tinham sido colegiais de São Paulo e de São Pedro, respectivamente, o que pode ajudar a perceber a situação. Assinale-se, para terminar, como durante este ciclo cresceu a percentagem dos deputados providos para bispos de dioceses.

\section{O governo da Inquisição}

A União Ibérica motivou a ausência quase contínua do rei do território de Portugal e, deste modo, a necessidade de estabelecer novos mecanismos de comunicação entre os organismos de governo do Santo Ofício, que ficaram em Lisboa, e a Coroa, agora em Valladolid e Madrid. Neste circuito intervieram diversas instituições, como o Conselho de Portugal, os vice-reis ou governadores e ainda diferentes juntas reunidas na corte. Mas, a despeito destas vias, o Santo Ofício tentou sempre criar um canal de acesso directo ao

${ }^{18}$ BA - GP, cód. 51-VIII-17, fl. 159r-159v e 9r, cartas de D. Pedro de Castilho a Felipe III (10-XII-1610) e (26-VII-1611); AHN - Estado, leg. 728, nº 17, consultas de duas juntas (20-VIII-1623 e 9-IV-1624). 
monarca, que evitasse a ingerência de intermediários. Para tal, experimentou três mecanismos diferentes.

Nos momentos de maior conflitualidade, o Santo Ofício recorreu ao envio de um inquisidor ou deputado do Conselho à corte, para impedir que a Coroa modificasse a estrutura ou o procedimento inquisitorial, interviesse na administração do fisco ou concedesse alguma mercê aos cristãos-novos. Foram essas as missões de Bartolomeu da Fonseca, em tempos de D. Filipe III, e de Sebastião de Matos de Noronha, D. Miguel de Castro e frei João de Vasconcelos, todos no reinado de D. Filipe IV.

Além do envio a Castela de deputados e inquisidores para fazer frente aos problemas que iam surgindo, o Santo Ofício recorreu à criação do cargo de agente da Inquisição na corte. Já em 1595 o Conselho Geral tinha exposto a necessidade de que em Madrid residisse uma pessoa encarregada das questões inquisitoriais, mas, nessa altura, o cardeal Alberto decidiu não introduzir novidades ${ }^{19}$. Como consequência dos intensos debates sobre o Santo Ofício dos anos anteriores ao perdão-geral de 1605, D. Pedro de Castilho nomeou o cónego Gonçalo Carreiro como agente do Santo Ofício na corte, em Fevereiro de $1606^{20}$. Embora o cargo, desempenhado depois por Gaspar Borges de Azevedo e por D. Fernão de Castro, tivesse prevalecido até 1619 , os inquisidores gerais cedo perceberam que não servia para impedir que as questões inquisitoriais fossem tratadas em diferentes conselhos e juntas.

Deste modo, foi preciso lançar mão de um outro expediente: a integração dos validos e dos secretários de Estado do Conselho de Portugal na própria instituição inquisitorial. Os inquisidores gerais e o Conselho sempre defenderam que os reis da casa de Áustria tinham reservado todos os negócios do Santo Ofício para o seu despacho pessoal, sem intervenção do Conselho de Portugal nem dos vice reis ou governadores ${ }^{21}$. E, mais uma vez, foi D. Pedro de Castilho quem consolidou as novidades na instituição que regia. Em 1608, propôs que o duque de Lerma, favorito de Felipe III,

${ }^{19}$ ANTT - CGSO, liv. 129, fl. 221r-222v, consulta do Conselho Geral (5-VIII-1595).

${ }^{20}$ ANTT - Inq. Lisboa, liv. 104, fl. 101v, provisão de D. Pedro de Castilho (6-II$-1605)$.

${ }^{21}$ ANTT - CGSO, liv. 323, fl. 38r-38v, consulta do Conselho Geral (17-V-1600) e resposta do bispo de Elvas. 
tratasse com o monarca os assuntos inquisitoriais ${ }^{22}$. Para tal contaria com a ajuda do secretário de Estado Fernão de Matos, nomeado também secretário da Inquisição, no ano de 1611. Depois do interim que constituiu o governo de D. Fernão Martins Mascarenhas (1616-1628), a partir de 1632, o novo inquisidor mor D. Francisco de Castro decidiu retomar o projecto de Castilho. Em Julho, proveu o secretário de Estado Diogo Soares como secretário da Inquisição em Madrid e, em Novembro, passou comissão ao conde-duque de Olivares para tratar, em seu nome, das questões inquisitoriais com D. Filipe IV. De acordo com o regimento para o secretário Soares, redigido por Castro, desde o regresso de D. Filipe II a Castela, em 1583, os sucessivos favoritos (o marquês de Castelo Rodrigo, o duque de Lerma e o conde-duque de Olivares) tinham-se encarregado de apresentar os negócios relativos ao Santo Ofício aos monarcas, e estes passaram a resolvê-los sem intervenção de nenhum outro ministro ou tribunal ${ }^{23}$.

Mas, a despeito do discurso do Tribunal e destes três meios postos em prática pelos inquisidores gerais para acederem directamente ao monarca sem intermediários, salvo os próprios validos, sabemos que a Coroa sempre consultou e tratou das questões do Santo Ofício com diferentes instituições portuguesas, como o Conselho de Portugal, e do conjunto da monarquia, como o Consejo de Estado e as diferentes juntas reunidas na corte.

\section{O Santo Ofício e os poderes do Portugal filipino}

Como assinalou Romero Magalhães, é fundamental proceder-se ao estudo dos vínculos entre o Santo Ofício e o resto dos poderes institucionais e corporativos, tanto seculares como eclesiásticos, do reino. Durante o tempo da União Ibérica, a colaboração e o entendimento caracterizaram as relações entre o inquisidor mor e o Conselho Geral, de um lado, e, do outro, os vice-reis ou governadores e os tribunais portugueses, como o Desembargo do Paço, a Casa da Suplicação e a Relação do Porto. Em Janeiro de 1580, o cardeal-rei D. Henrique ordenou que, sempre que fosse necessário resolver dúvidas

${ }^{22}$ ANTT - CGSO, liv. 92, fl. 136v, carta de D. Pedro de Castilho a Felipe III (12-V$-1600)$.

${ }^{23}$ ANTT - CGSO, liv. 353, Regimento e instrucção pera o secretario de estado e inquisiçam que assite na corte de Madrid pella coroa de Portugal. 
motivadas pelos privilégios dos ministros, oficiais e familiares do Santo Ofício, se reunissem dois deputados do Conselho e dois desembargadores do $\mathrm{Paço}^{24}$. Em nosso entender, estas juntas, embora não sendo muito numerosas - apenas dez até 1640 -, constituíram um modo pacífico e consensual de solucionar os problemas de jurisdição entre instituições.

Os conflitos mais importantes relacionaram-se com as pretensões do Santo Ofício em mostrar um status superior ao das restantes instituições. Assim, por exemplo, os deputados do Conselho precederam desde sempre os desembargadores do Paço nas juntas, e este costume foi confirmado por D. Filipe IV em $1626^{25}$. Por seu turno, os inquisidores consideravam que as justiças seculares tinham a obrigação de obedecer às suas ordens. Isto originou, em 1618, uma acesa altercação entre Sebastião de Matos de Noronha, que estava a realizar a visita inquisitorial ao distrito de Coimbra, e D. Diogo Lopes de Sousa, governador da Relação do Porto. Como corolário das disputas entre ambos, a Inquisição processou o juiz dos órfãos da cidade, o procurador da coroa na comarca e três oficiais da Relação. Mas, exceptuando este confronto, o Tribunal da Fé e os restantes tribunais do Reino mantiveram uma convivência pacífica durante todo o tempo dos Áustrias.

A colaboração ou, pelo menos, a ausência de conflito também caracterizaram as relações entre o Santo Ofício, de um lado, e os bispos e as ordens religiosas, do outro. Existem, é verdade, alguns episódios de desavenças entre o Santo Ofício e os prelados, motivados por questões de precedência nos autos públicos da fé. Mais importantes, em nosso entender, foram as disputas motivadas pela pretensão do Santo Oficio de ter jurisdição privativa sobre certos crimes mixti fori, como a bigamia, a feitiçaria, dizer missa ou ouvir em confissão sem ter ordens maiores, ou a solicitação. No entanto, estes choques, normais entre instituições eclesiásticas, não impediram a colaboração das autoridades episcopais e inquisitoriais na perseguição da heresia.

${ }^{24}$ Alvará de D. Henrique de 20 de Janeiro de 1580, publicado no Traslado autentico de todos os privilegios concedidos pelos Reys destes Reynos, \& senhorios de Portugal aos Officiaes, \& Familiares do Santo Officio da Inquisição. Lisboa: Miguel Manescal, 1685.

${ }^{25}$ ANTT - CGSO, liv. 88, Portarias, fl. 60, carta de D. Filipe IV (3-VI-1626). 
Muito interessantes, embora muito menos estudadas, são as relações entre o Tribunal da Fé e os cabidos das sés do Reino, caracterizadas pela fricção motivada pelo privilégio de non residendo. Graças a indultos papais chamados quinquénios, os ministros do Santo Ofício podiam receber os frutos dos seus benefícios sine cura sem cumprir a obrigação de residência. Os cabidos não se opuseram ao privilégio em si, mas tentaram limitar a sua aplicação no caso dos deães e dos cónegos magistrais e doutorais. Isto gerou periódicos conflitos que tiveram de ser resolvidos em Roma e que perduraram durante o resto do século XVII e do XVIII.

Por último, em Portugal existia um outro tribunal apostólico, o do colector. Contrariamente ao que ocorreu na época do estabelecimento da Inquisição, ou seja, no tempo dos núncios Luigi Lippomano e Giovanni Ricci, no período dos Filipes a intervenção do colector em questões relativas ao Santo Ofício não foi provocada por pressões dos cristãos-novos, mas sim por motivos económicos e jurisdicionais. Por um lado, os colectores desejavam cobrar os quindénios das pensões e benefícios inquisitoriais, tal como os bens dos clérigos condenados pelo Santo Ofício. Por outro lado, pretendiam constituir-se como juízes de apelação das sentenças inquisitoriais nas causas que não fossem de fé, isto é, nas motivadas pelo foro inquisitorial e pelos beneficios in absentia. Mas, no final da União Ibérica, ainda não tinham conseguido nenhum destes dois objetivos.

\section{O Tribunal da Fé perante o devir político}

A instituição inquisitorial, assim como os seus membros, assistiram às duas grandes crises que assinalam o início e o fim do tempo dos Filipes. O Santo Ofício não reagiu como um bloco compacto e uniforme nem perante a agregação de Portugal à Monarquia Hispânica, nem perante a sua separação. Assim, depois da morte de D. Sebastião, tanto D. Jorge de Almeida, novo inquisidor geral, como Paulo Afonso, o jesuíta Jorge Serrão, e António de Mendonça, deputados do Conselho, mantiveram uma atitude de cautela e expectativa sem apoiar nenhum dos pretendentes ao trono até à vitória militar do duque de Alba, na batalha de Alcântara, a 25 de Agosto de 1580 . 
Também em 1640 a Inquisição não reagiu em bloco. Por isso, não faz sentido considerar o Santo Ofício como uma instituição pró-filipina ou pró-bragançista perante a Restauração, como têm feito alguns autores. Impõe-se uma maior precisão, isto é, analisar os vínculos e as decisões políticas de cada um dos seus membros. Deste modo, é possível comprovar que houve ministros do Tribunal que participaram na conspiração de 1640, como os inquisidores de Lisboa Pantaleão Rodrigues Pacheco e Diogo de Sousa, enquanto que outros tiveram de se exilar em Castela, como o inquisidor de Évora António da Silveira ou o de Lisboa D. Álvaro de Ataíde. Também no Conselho Geral existiram diversas opções políticas: Sebastião César de Meneses apoiou desde cedo o regime Bragança, D. Luis de Melo fugiu para Castela e frei João de Vasconcelos manteve uma atitude muito crítica com o novo governo. O próprio inquisidor geral, D. Francisco de Castro, participou na conjuração pró-filipina descoberta a 28 de Julho de $1641^{26}$.

Entre 1580 e 1640, a actuação da Coroa sobre o Santo Ofício materializou-se nas tentativas de reformar o Tribunal, como consequência, na maior parte das vezes, das críticas dos cristãos-novos. Estes recorreram à táctica de contrapor a justiça do procedimento inquisitorial espanhol à iniquidade do português e, em alguns casos, chegaram, inclusivamente, a propor a união dos dois tribunais ibéricos ${ }^{27}$. Os debates sobre o procedimento inquisitorial português foram constantes nos reinados de D. Filipe III e D. Filipe IV e, no primeiro deles, discutiu-se, igualmente, o tema da reforma institucional do Santo Oficio. O Tribunal sempre temeu que destas discussões resultasse a sua submissão, ou até união, ao Santo Ofício espanhol. Por isso, opôs-se

${ }^{26}$ Relação de tudo o que passou na felice aclamação do mui alto e mui poderoso rey Dom Ioão o IV. Lisboa: Lourenço de Anveres, 1641, p. 25.

${ }^{27}$ LÓPEZ-SALAZAR CODES, Ana Isabel - Che si riduca al modo di procedere di Castiglia. El debate sobre el procedimiento inquisitorial portugués en tiempos de los Austrias. Hispania Sacra. Vol. LIX, no 119 (2007) 243-268. MARCOCCI, Giuseppe - A Inquisição portuguesa sob acusação: o protesto internacional de Gastão de Abrunhosa. Cadernos de Estudos Sefarditas. 7 (2007) 31-81. Também defenderam a existência de um só inquisidor geral aqueles que, como don Diego de Torquemada bispo de Tuy, estavam contra o modelo de agregação das coroas expresso nos artigos de Lisboa de 1499. Archivo General de Simancas, Estado, Portugal, leg. 412, fol. 61, cf. BOUZA ÁLVAREZ, Fernando-Portugal en la Monarquía Hispánica (1580-1640): Felipe II, las cortes de Tomar y la génesis del Portugal católico. Madrid: Universidad Complutense, 1986, p. 229-230. 
sempre aos projectos de reforma apresentados pela Coroa e consolidou a sua própria estrutura e o seu procedimento nos sucessivos regimentos de 1613 e de 1640.

\section{Conclusão}

Do exposto resulta que durante os sessenta anos da União Ibérica, o Santo Ofício experimentou transformações institucionais, governativas e sociológicas. Assim, naquela época, os inquisidores-gerais passaram a exercer o cargo em exclusividade, pois foram obrigados a renunciar aos bispados de que eram titulares até terem sido nomeados para a direcção do Tribunal da Fé. No Conselho Geral aumentou-se o número de deputados, passando de três, quantitativo que estabelecia o Regimento de 1570, do tempo de D. Henrique, a um máximo de seis, um dos quais seria sempre membro da Ordem de São Domingos. Além disso, devido à permanência da corte em Madrid, foi preciso criar novos canais de comunicação institucional entre o Santo Oficio e a Coroa. Por último, do ponto de vista social, verificou-se um incremento do estatuto dos inquisidores-gerais com D. Fernão Martins Mascarenhas e, sobretudo, com D. Francisco de Castro, por comparação com os que os precederam no final da década de noventa e nos inícios de Seicentos, a saber, D. António Matos de Noronha e Pedro de Castilho. Esta transformação foi acompanhada do ingresso no Conselho - anteriormente feudo de letrados - de personagens provenientes da fidalguia.

Este conjunto de alterações, todavia, não foi acompanhado por mudanças radicais no procedimento inquisitorial português, o qual tinha sido um dos aspectos mais debatidos na Corte durante a União Ibérica, em grande parte devido às pressões e súplicas que ali eram levadas pelos cristãos-novos. Assim, embora as Juntas reunidas em Valhadolid para a reforma do Santo Ofício, em 1603 e 1604, e as posteriormente convocadas por D. Filipe IV nos primeiros anos de seu reinado tivessem abordado diferentes questões judiciais - como o problema das testemunhas singulares ou o tipo de pena a aplicar aos reconciliados - o Santo Ofício lusitano conseguiu preservar incólume a sua própria prática, e evitar a intervenção da Coroa no modo de proceder no tocante às causas da fé. Em suma, apesar de alguma 
agitação, a Inquisição portuguesa sempre manteve a sua autonomia. Como escreviam os deputados do Conselho Geral, em 1604, "he milhor gardarse o estillo de que ategora se usou que mudalo"28. E assim foi, basicamente, até 1640 .

${ }^{28}$ BNL - FG, cód. 1537, fl. 119r-125r, resposta do Conselho Geral aos capítulos da primeira junta. 